\title{
Renewable Energy Transition: A Market-Driven Solution for the Energy and Environmental Concerns in Chile
}

\author{
Claudio A. Agostini ${ }^{1} \quad$ Shahriyar Nasirov $^{2}$ Carlos Silva $^{3} \quad$ Gustavo Cáceres $^{4}$
}

\begin{abstract}
:
Chile is undergoing a remarkable energy matrix transition to renewable energy. Renewable energies are expanding extraordinarily quickly, exceeding earlier predictions. As a result, the country is expected to meet its 2025 goal of generating $20 \%$ of its electricity from renewable energy sources quite before. Chile has become one of the first countries in the world with subsidy-free markets, where renewable projects compete directly with other conventional sources. Favorable market conditions and successful policy reforms were keys to fostering this renewable energy development. Although the country has achieved a substantial growth in renewable energy investment in relatively short periods of time, this optimism should be treated with caution. A successful transition requires a combination of a clear decision making, persistent and consistent government policies, and a clear commitment to tackling challenges to accommodate renewable energy in the power system. In this context, this paper analyses the Chilean renewable industry and the required government policies to succeed in this transition. For this purpose, we identify several critical factors that have attracted and that could attract investment to the renewable energy sector and propose key recommendations to effectively address the major challenges faced for the future development of the industry.
\end{abstract}

Keywords: Energy Transition, Energy Policy, Renewable Energy Technologies, Chile

\footnotetext{
${ }^{1}$ Escuela de Gobierno, Universidad Adolfo Ibañez

${ }^{2}$ Facultad de Ingeniería, Universidad Adolfo Ibañez

${ }^{3}$ Facultad de Ingeniería, Universidad Adolfo Ibañez

${ }^{4}$ Facultad de Ingeniería, Universidad Adolfo Ibañez
} 


\section{Introduction:}

Over the last few years, Chile has experienced a remarkable energy transformation. The investors' interest in renewable energies has been increasing rapidly. Despite a relatively small energy market, Chile became the second largest market, after Brazil, for renewable energy investment in South America. Investment -excluding large hydro- reached a record level of about USD 2.4 billion in 2015 ( BNEF,2016), making an accumulated investment of around US\$ 9.2 billion between 2013 and 2015. It is expected to grow even further. In the same year, $76 \%$ of the overall investment in electricity generation came from renewable energy technologies, demonstrating the crucial role played by this industry. Chile ranked 10 th in the list of top worldwide investing countries in the renewable industry in 2015 (REN21, 2016). Another essential feature of Chilean renewable industry is the financially self-sustainability of this market as Chile is one of the first subsidy-free large markets, where renewable projects can compete directly with other conventional sources.

Chile's power sector had 20,080 MW of installed capacity and 66,8 GWh of energy generation in 2015 (CNE, 2015). The installed capacity in renewable energy sources has increased sharply in recent years, from $720 \mathrm{MW}$ in 2011 to 3,119 MW in 2016 (see table 1). This corresponds to $15 \%$ of the total installed power capacity in the system, having then already met and even surpassed the quota defined by the Renewable Law No. 20,257 for the year 2016. Among the different technologies, solar energy contributes to RES-installed capacity with 1,267 MW, representing the largest share of renewables in the country with 41\%. In addition, there are currently RES projects under construction for 2,336 MW and a significant fraction of them are solar energy projects. As shown in Table 1, there also exists a significant number of renewable projects either with environmental approval or under evaluation, which will significantly increased the total generation installed capacity once 
they are constructed. These numbers show a promising future for the development and deployment of renewable energy technologies in Chile. As a result, it is expected that the established 2025 target of $20 \%$ of electricity generation in the country coming from renewable energy sources will be met quite ahead of schedule.

Table 1: Renewable Energy Development Trends in Chile between 2011 and 2016

\begin{tabular}{cccccccccc}
\hline Technology & $\begin{array}{c}\text { Resource } \\
\text { Potential } \\
(\mathbf{G W})\end{array}$ & $\begin{array}{c}\text { Operating } \\
(\mathbf{M W})\end{array}$ & \multicolumn{2}{c}{$\begin{array}{c}\text { Under } \\
\text { construction } \\
(\mathbf{M W})\end{array}$} & $\begin{array}{c}\text { Approved } \\
\text { SEIA (MW) }\end{array}$ & $\begin{array}{c}\text { Under } \\
\text { evaluation } \\
\text { SEIA (MW) }\end{array}$ \\
\hline Year & & 2011 & 2016 & 2011 & 2016 & 2011 & 2016 & 2011 & 2016 \\
\hline Small Hydro & 23 & 246 & 435 & 64 & 25 & 368 & 455 & 93 & 95 \\
\hline Solar & 228 & 0 & 1,267 & 1 & 1,786 & 467 & 13,123 & 302 & 6,704 \\
\hline Bio technology & 10 & 270 & 470 & 170 & 0 & 55 & 120 & 49 & 67 \\
\hline Wind & 40 & 205 & 947 & 6 & 477 & 2,269 & 6,500 & 1,041 & 1,949 \\
\hline Geothermal & 16 & 0 & 0 & 0 & 48 & 0 & 120 & 50 & 0 \\
\hline Total & & $\mathbf{7 2 0}$ & $\mathbf{3 , 1 1 9}$ & $\mathbf{2 4 2}$ & $\mathbf{2 , 3 3 6}$ & $\mathbf{3 , 1 5 9}$ & $\mathbf{2 0 , 3 1 8}$ & $\mathbf{1 , 5 3 5}$ & $\mathbf{8 , 8 1 5}$ \\
\hline
\end{tabular}

Sources: Own elaboration based on data from CIFES, 2016

Projects using renewable technologies are particularly attractive in Chile because the country is endowed with a significant variety of renewable energy sources, all of which have a high potential to generate significant amounts of electricity. In particular, a significant potential in biomass, hydropower, geothermal, solar, wave, and wind energies have not been fully exploited yet. The estimated potential of renewables in Chile is summarized in Table 1. Endowed with over 2,653 miles of coastline and the suitable characteristics of waves due to the presence of large swells usually found in great oceans, makes Chile one of the most appropriate sites in the world for the energy generation from the waves. The country also has 
a large geothermal potential, as $10 \%$ of the most active volcanoes in the world are situated in its territory. It has also a promising small hydropower potential in various locations along central and southern territories. The climate in the Atacama Desert in northern Chile possesses ideal conditions for solar energy, as it receives an annual $0.6 \mathrm{~mm}$ of rainfall, it is known as one of the driest places on earth, and it receives the highest irradiance in the world. Moreover, an attractive investment climate was also a key encourage factor in promoting large scale renewable energy investments. Over the past 20 years, Chile has offered private investors a very favorable investment climate. It is one of the most successful countries in South America in terms of institutional and political stability, sound macroeconomic policies, and market-oriented reforms. As a result, the country has achieved an extraordinary economic expansion over the last 30 years, leading to a large scale poverty reduction. The high and sustained rate of economic growth, together with the institutional reforms implemented, allowed Chile to become the only country in South America to be a member of the Organization of Economic Cooperation and Development (OECD, 2009).

Although favorable investment environment and an abundance of natural resources are key factors in fostering the development of renewable energy, the leadership of the Chilean government through successful policy reforms has also been fundamental in the energy transition of the country. This article analyses the renewable energy policy making in Chile, identifying driving factors behind the energy transition, and highlighting the government main policy actions. It also gives important policy recommendations for effectively addressing the coming challenges for future development of the industry. The article continues with the following sections. Section 2 describes the driving forces that have behind the energy transition; Section 3 discusses government policies; and finally, Section 4 conlcudes and makes policy recommendations. 


\section{Driving Forces behind the Energy Transition}

As many countries, Chile is committed to undertaking the transition toward a low carbon energy system. Globally, the rapid expansion of renewables as mainstream sources of energy in this transition is mostly due to technological advancements that have reduced their cost and also due to growing environmental awareness in the population. In the case of Chile, there are additional drivers that have encouraged investments in renewable energies. More specifically, the increase in energy consumption, the high energy dependency from external sources, the increasing cost of imported energy, and the failure of large energy projects due to environmental concerns have all played a positive and significant role.

\subsection{Increasing energy consumption}

Over the past decade, Chile's exceptional macroeconomic performance and the subsequent improvement in its population's welfare has created a significant boost in energy demand and a need for critical energy infrastructure. Today, Chile ranks as the highest energy consumption per capita in South America well ahead of larger countries such as Argentina Brazil and Colombia (World Bank, 2015) ( See, Figure 1). According to a forecast conducted by the National Energy Commission (CNE), between 2015 and 2030, the energy consumption in Chile is expected to grow from $66,7 \mathrm{TWh}$ to $120,7 \mathrm{TWh}$ with an annual

growth of 4,1 percent. The country's single largest industry -mining- and the residential sector of the largest urban area, Metropolitan Santiago that alone contains almost $40 \%$ of the population, contribute the largest part of energy consumption. 
Figure1: Electric power consumption (kWh per capita) in South American countries

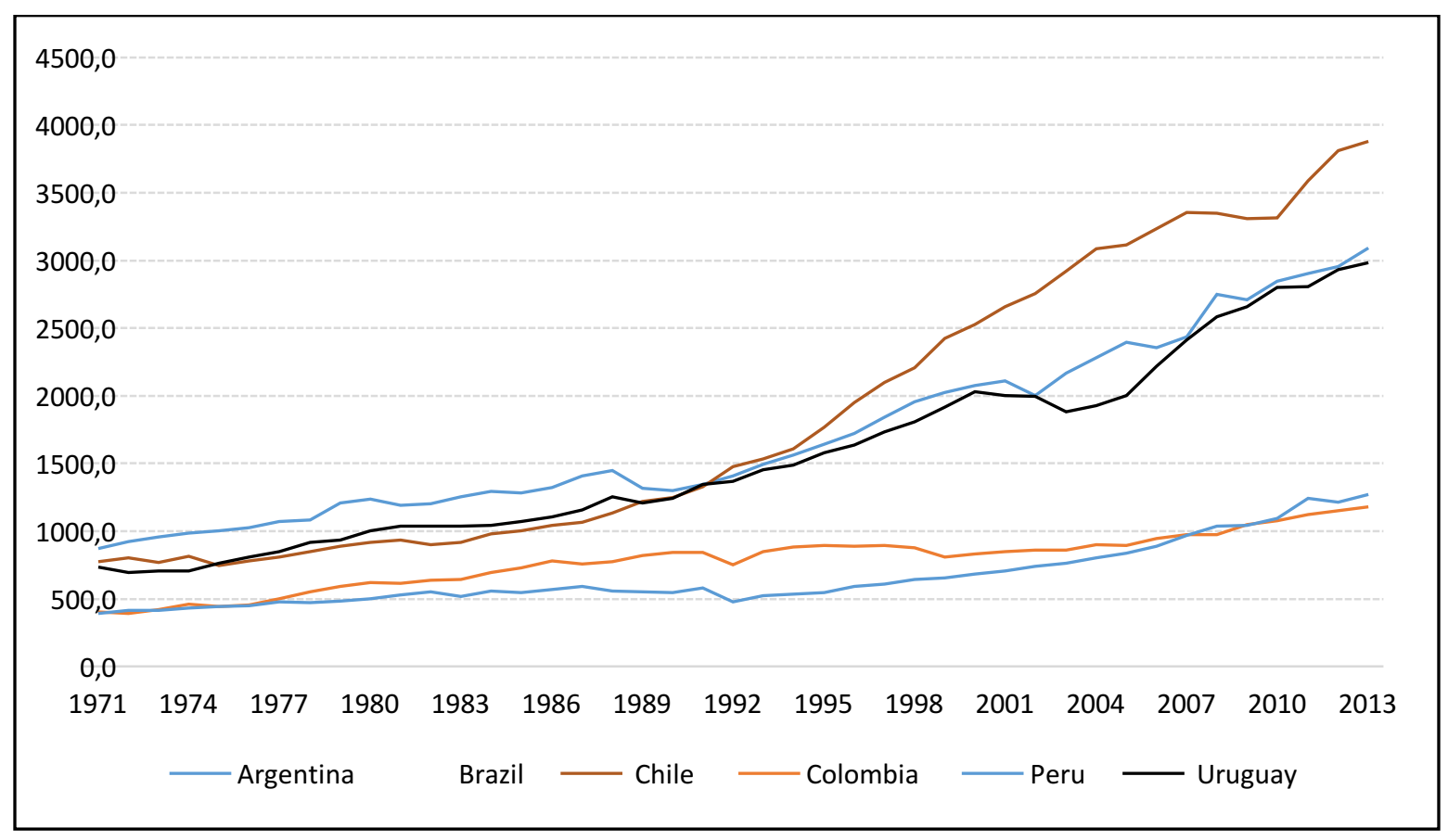

Sources: Own elaboration based on data from World Bank, 2014

\subsection{Increasing energy dependency from external sources}

The significant restructuring of the electricity industry in the late 1980s, implied a shift in the energy sector from a state-owned system towards one based on the principle of a free and competitive market. Even though numerous reforms sought to improve productive efficiency and generate a strong competitive market, Chile lacked a clear, certain and comprehensive policy on energy diversification. For several decades, the country has been very vulnerable in terms of energy security and it has struggled to obtain a reliable energy matrix. In the 1980s, it relied heavily on hydro power resources, with an energy matrix contribution between $70 \%$ and $80 \%$ of the total electric system installed capacity. The remaining energy sources of the matrix were provided by imports of oil and coal. (See fig 2.). 
However, during late 1980s, the power system started facing serious pressure from continued rapid growth in the energy demand and mounting concerns regarding the availability of hydro energy due to adverse dry weather conditions. The need to guarantee the supply of electricity, independent from the prevailing weather conditions, and the increasing demand, convinced policy makers and investors to import relatively cheap natural gas from Argentina. For that purpose, in 1995, a protocol was signed between Chile and Argentina to connect both countries with long gas pipelines crossing the Andes Mountains. As a result, the sector invested heavily in pipelines, new gas distribution facilities and natural gas power plants, as well as in infrastructure to substitute more expensive and less clean fuels in the existing industrial processes. The change also required minor housing investments for the well functioning of many appliances as they were designed to work with liquefied petrol gas and not with natural gas. Relatively clean and low cost imported natural gas from Argentina made natural gas plants more attractive than large coal plants and less risky than hydro plants. In 2004, Chile imported about 18.5 million $\mathrm{m}^{3}$ of natural gas per day from Argentina, representing almost $15 \%$ of Argentina's natural gas production and around 26\% of Chile's total energy consumption ( Raineri, 2007). However, the reliance on Argentinean natural gas proved to be highly disruptive when the Argentinian government decided to set stringent export constraints on natural gas because of its growing internal demand and market disequilibrium due to severe price distortions and macroeconomic imbalances. A short period after, Argentina clearly became a non-reliable partner and quite soon it reached the point where gas supply practically halted in 2008 . The natural gas shortage brought about another energy crisis in Chile where generators were forced to replace gas-fired electricity with expensive diesel operation. The collapse of Argentinean gas exports renewed the attention of investors to the development of large hydro projects and coal plants as reasonable 
alternatives. As a result, coal fired power capacity grew substantially until it quadrupled to $5,150 \mathrm{MW}$ in 2016 , accounting for $23 \%$ of the total electricity generation in Chile. Around $85 \%$ from this coal was imported from Colombia (40\%), Indonesia (30\%) and Australia $(15 \%)$ ( Nasirov, 2014). As seen in Figure 2, starting from early 1990s, the Chilean energy matrix has transformed from mostly domestic sources of energy to predominantly imported sources. As of today, dependency of external sources represents around $60 \%$ of the energy matrix in the form of natural gas, coal and diesel. The remaining $40 \%$ consists of large hydroelectric resources and non-conventional renewable energy sources due to recent investments. This heavy dependence on energy imports positions the country at a higher risk of global market trends and uncontrollable climate events as well as political and market related risks.

Figure 2: Energy Imports $(+)$ and Energy export (-), (\% of Energy Use)

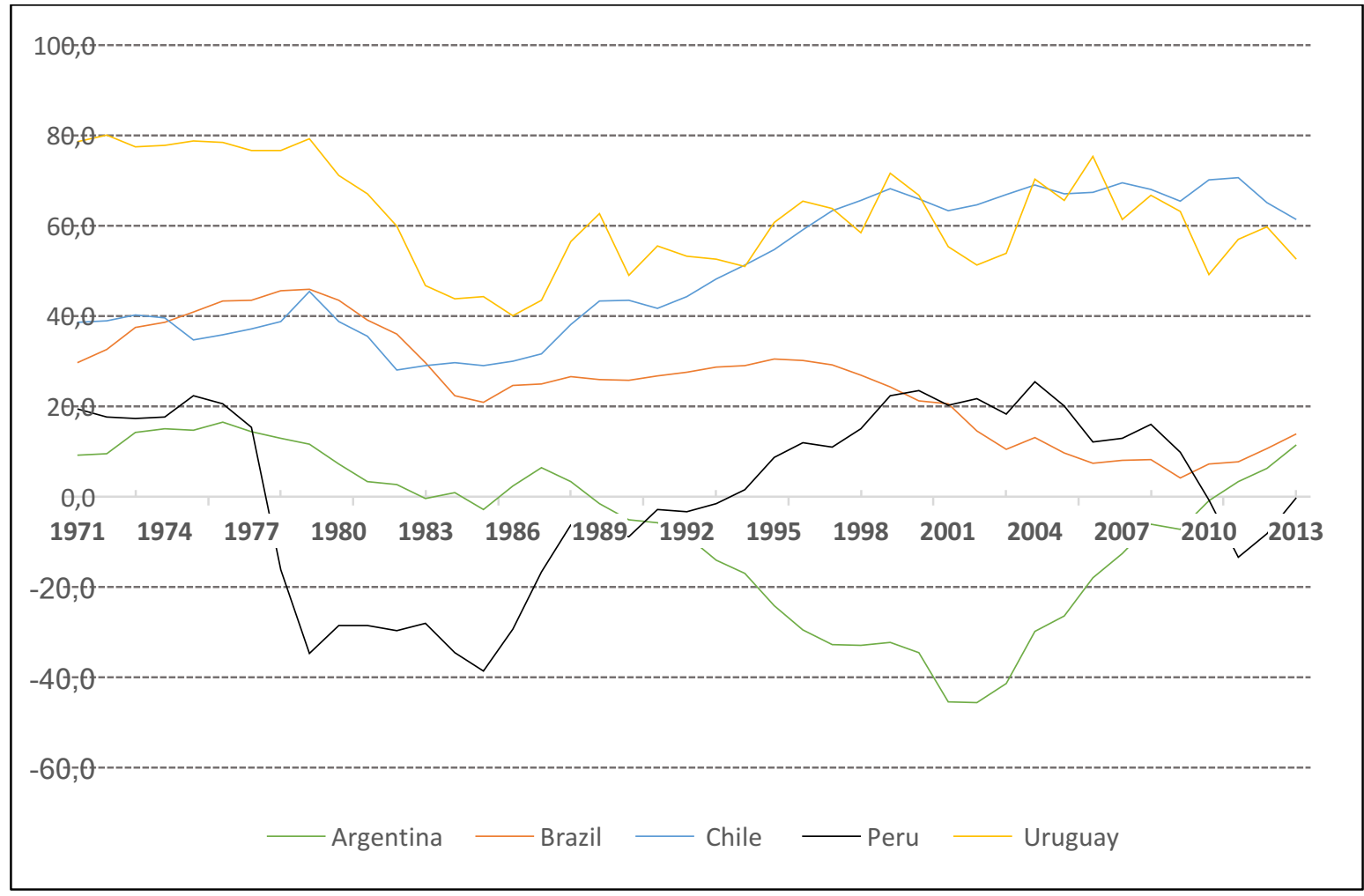

Sources: Own elaboration based on data from World Bank, 2014 


\subsection{Increasing cost of energy}

The mix between an energy matrix increasingly dependent on imported sources and a growing energy demand have resulted in high and unstable electricity costs for both households and industries. In fact, electricity prices doubled in the past decade and they have just recently declined as a result of the decreased in international oil prices. The perspectives regarding future prices are unclear, especially if the country does not find a solution for its heavily dependence on imported energy. During the gas crisis with Argentina, the marginal costs in the spot market increased from US\$46/MWh in 2006 to US\$300/MWh in 2008, when it reached its record level, and now decreased to US\$40/MWh in 2016 ( CDEC-SIC, 2010). The large variation in energy prices has made difficult to predict energy costs when evaluating projects and, as a result, several investments were postponed. The effects were especially relevant in the mining industry, where the cost of energy represents about 20-30\% of its total cost of production . Given that the mining industry accounts for $20 \%$ of GDP and $60 \%$ of exports in the country, negative shocks affecting it significantly spread out over the whole economy. Today, the cost of energy in the Chilean mining industry is one of the highest in the world with $12.1 \mathrm{c} / \mathrm{kWh}$, facing a large disadvantage with respect to its competitors. For example, in Peru, a neighboring mining country, the cost of energy is cheaper and more stable, with $6.6 \mathrm{c} / \mathrm{kWh}$, in Mexico is $9.0 \mathrm{c} / \mathrm{kWh}$, is USA is $7.5 \mathrm{c} / \mathrm{kWh}$ and in Canada is around $5.3 \mathrm{c} / \mathrm{kWh}$ ( Villarino, 2012).

\subsection{Increasing greenhouse gas emissions}

A heavy reliance on natural resources explotation has historically constituted the backbone of Chilean economic growth. Unfortunately, this strong economic growth with based mostly on natural resources has come at the cost of the environment and resulted in accumulated 
severe environmental degradation causing high social and ecological costs. Over the last few years, increasing environmental concerns and more ambitious social objectives have questioned the long-term sustainability of the economic development.

Although Chile contributes with only 0.28 percent of the world's greenhouse gas emissions, its per-capita emissions have been increasing over the last two decades. Between 1990 and 2010, Chile's greenhouse gas (GHG) emissions -excluding land use, land-use change and forestry- increased by $84 \%$, reaching 5.3 tons per person. That makes it the second-largest per-capita climate polluter in Latin America after Venezuela, and one of the largest among OECD member countries ( OECDb, 2016). While CO2 is the largest component of GHG emissions in Chile, contributing $77 \%$ to its total emissions, methane (CH4) and nitrous oxide (N2O) accounted for the remaining 23\% in 2010. Energy production and consumption constituted the largest part of all emissions, accounting for $75 \%$ of the total GHG emissions in 2010. The sharp increase in GHG emissions is also largely due to the shift from natural gas to more carbon-intensive fuels (coal and diesel) for electricity generation in the second half of the 2000s. Since 1990s, poor air quality due to the emissions of major air pollutants became a main public health concern across the country, particularly in large metropolitan areas, and also in the surroundings of large industrial and mining sites. Air pollution in Santiago, the country's capital, and also Temuco and Coyhaique in the south, has become a serious environmental and health problem, as in those cities it often exceeds the critical levels suggested by the World Health Organization. According to the first national survey on the environment implemented by the Ministry of Environment in 2015, two out of three Chileans are very concerned about environmental issues and consider air pollution as the biggest environmental problem followed by urban waste and noise pollution . At the national level, the emission of key air pollutants as PM2.5, PM10 and carbon monoxide (CO) increased by 
roughly 14\% between 1990 and 2010 and emissions of nitrogen oxides (NOx) nearly doubled over that period.

Figure 3: CO2 emissions (metric tons per capita)

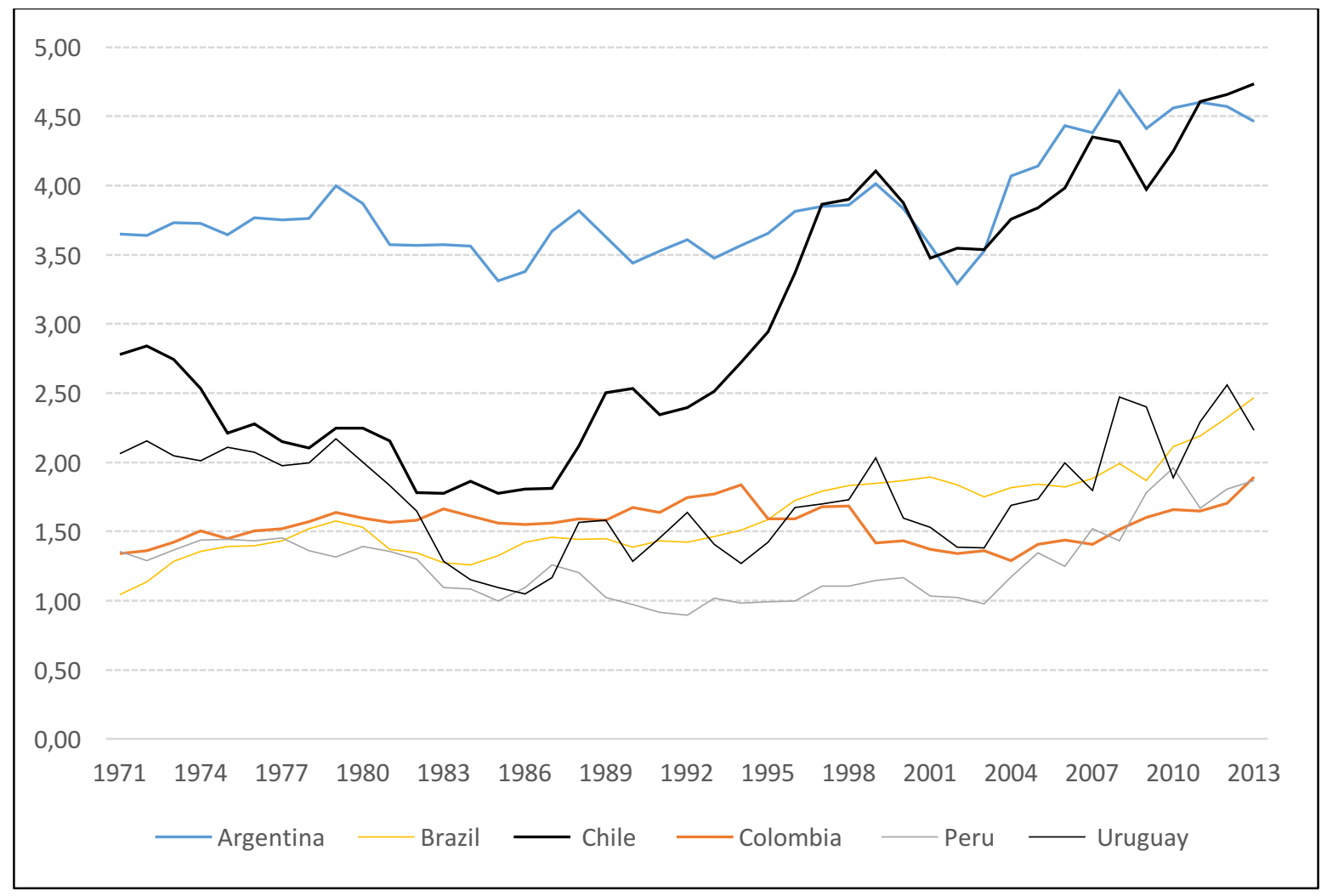

Source: Own elaboration based on data from World Bank, 2014

\subsection{Failure of large energy projects due to environmental and social concerns}

Another important factor in Chile's energy transition is the growing socio-environmental concern faced by large traditional energy projects. Given the role played by natural resources in th economy, policy decisions have usually prioritized economic growth over any environmental and social concern. Over the last decade, the electricity sector in Chile experienced a very rapid expansion of energy infrastructure involving the construction of large power plants, mainly diesel and coal. The key policy decisions behind these expansions were based on giving a high priority to economic growth, while environmental and social 
concerns were perceived mainly as a restraining factor. With the restoration of democracy after the Pinochet regime, however, public social and environmental awareness increased and it was also possible to expres them. As a result, the country's conventional energy system has been targeted in mass protests. Over the past few years, communities, investors, and the government have clashed over the Social and Environmental Impact Assessment (EIA) evaluations of large energy projects.

In Chile, environmental protection policies were established for the first time in mid-1990s, when an environmental law (no. 19.300) was approved. This was partly the result of external pressure from multilateral and bilateral funding agencies and international organisations such as the United Nations Environment Programme (UNEP) and Non-Governmental Organisations (NGOs). Nevertheless, the country still faces the challenge of strengthening its legal framework, as well as developing its organizational capacity to address the potentially significant environmental impacts of large energy projects and industrial activities. As of today, increasing environmental concerns and more ambitious social objectives have questioned the long-term sustainability of many large energy projects. Eventually, this has led to a growing and strong opposition to many of the new energy projects from local communities and also from social and environmental movements. Projects are being questioned because of their impact on wildlife habitats, on cultural and natural heritage, on water quality and erosion, and, more recently, on the landscape of untouched regions. In addition, there is an increasing questioning of the decision-making process for the approval of energy projects, as people felt that spaces for effective participation were inadequate and that the distribution of costs and benefits was unfair. As a result, many energy projects using different technologies and located in different regions of 
the country have suffered a long delay in their approval processes, and most of them ended up either rejected or challenged in court due to a weak and flawed environmental review system. In fact, this is true for most of the large energy projects successfully completed, such as the Ralco and Pangue dams in the Bio-Bio river (720MW and 450MW respectively) in the 1990s, and some postponed or cancelled, such as the Barrancones coal plant (540MW) in 2010, and, more recently, the HidroAysen mega-dam complex $(2,750 \mathrm{MW})$ in the Patagonia in 2013 (Lostarnau et al., 2013, Nelson, 2013, Orellana, 2005).

Table 2: Energy Mega-Projects failed in Chile

\begin{tabular}{|c|c|c|c|c|c|}
\hline \multirow[b]{2}{*}{ Project } & \multirow[b]{2}{*}{ Technology } & Capacity & \multirow{2}{*}{$\begin{array}{l}\text { Flooded Area } \\
\text { (ha) }\end{array}$} & \multicolumn{2}{|l|}{ EIA } \\
\hline & & $(\mathrm{MW})$ & & Presented & EIA Approved \\
\hline HidroAysen & Hydropower & 2750 & 5910 & August 2008 & May 2011 \\
\hline Pangue & Hydropower & 450 & 500 & & \\
\hline \multirow[t]{2}{*}{ Ralco } & Hydropower & 692 & 3500 & March 1996 & June 1997 \\
\hline & & & & December & \\
\hline \multirow[t]{2}{*}{ Castilla } & Coal & 2100 & & -2008 & - \\
\hline & & & & December & \\
\hline Barrancones & Coal & 540 & & - 2007 & September 2010 \\
\hline
\end{tabular}

\section{Government Policy Actions}

A mix of different factors mobilized Chilean government to search for additional sources of energy to foster more reliable supplies. On the one hand, there was an increasing energy 
demand. On the other hand, there was, a high risk of the hydropower generation during the drought periods, a rising dependence on external energy sources, and a growing environmental and social concerns on traditional power projects.. Renewables seemed, therefore, an important addition to the country's energy diversification strategy. Possessing great potential in terms of natural resources provides a significant comparative advantage to become an ideal marketplace for renewable power developers. Most importantly, favorable business climate and high electricity prices in the country have also turned out to be an advantage for renewable energy projects, making them profitable and competitive. Although the Chilean energy market offers favorable conditions for project developers, the leadership of the government through successful policy reforms has also been fundamental in the energy transition of the country. In fact, the government has introduced several incentive mechanisms for supporting and promoting renewable energy technologies in the country, all of which have had a positive impact.

\subsection{Approval of a Renewable Energy Law}

The first important reform for the renewable energy sector was the approval of a Renewable Energy Law, which included Renewable Portfolio Standards (RPS). Throughout the South American region, the support mechanisms used for promoting renewable energy sources vary from country to country. Table 3 describes the different support mechanisms offered in the most relevant South American countries for this purpose. The different policies chosen to support the participation of renewable energy in the region follow different backgrounds and motivations. Introducing a Renewable Portfolio Standards (RPS) model for energy from generators as the major regulatory support mechanism basically follows the international trend. It is a quota obligation system, which encourages renewable energy generation by 
setting the proportion of electricity supply that must be produced from eligible renewable energy sources. The introduction of non-conventional renewable energy technologies for the first time in the energy matrix in Chile dates back to 2008 with the approval of Law No. 20,257. The law aimed to support the generation of electricity from RES, considering for this purpose the following main renewable energy sources: biomass, small hydraulic energy (capacity of less than $20 \mathrm{MW}$ ), geothermal energy, solar energy, wind power, and marine energy. This law was amended in 2013 (Law 20,698, better known as "Law 20/25") stating that by $2025,20 \%$ of the energy matrix in Chile must be composed of renewable energy.

Table 3: Supporting Mechanisms in South America

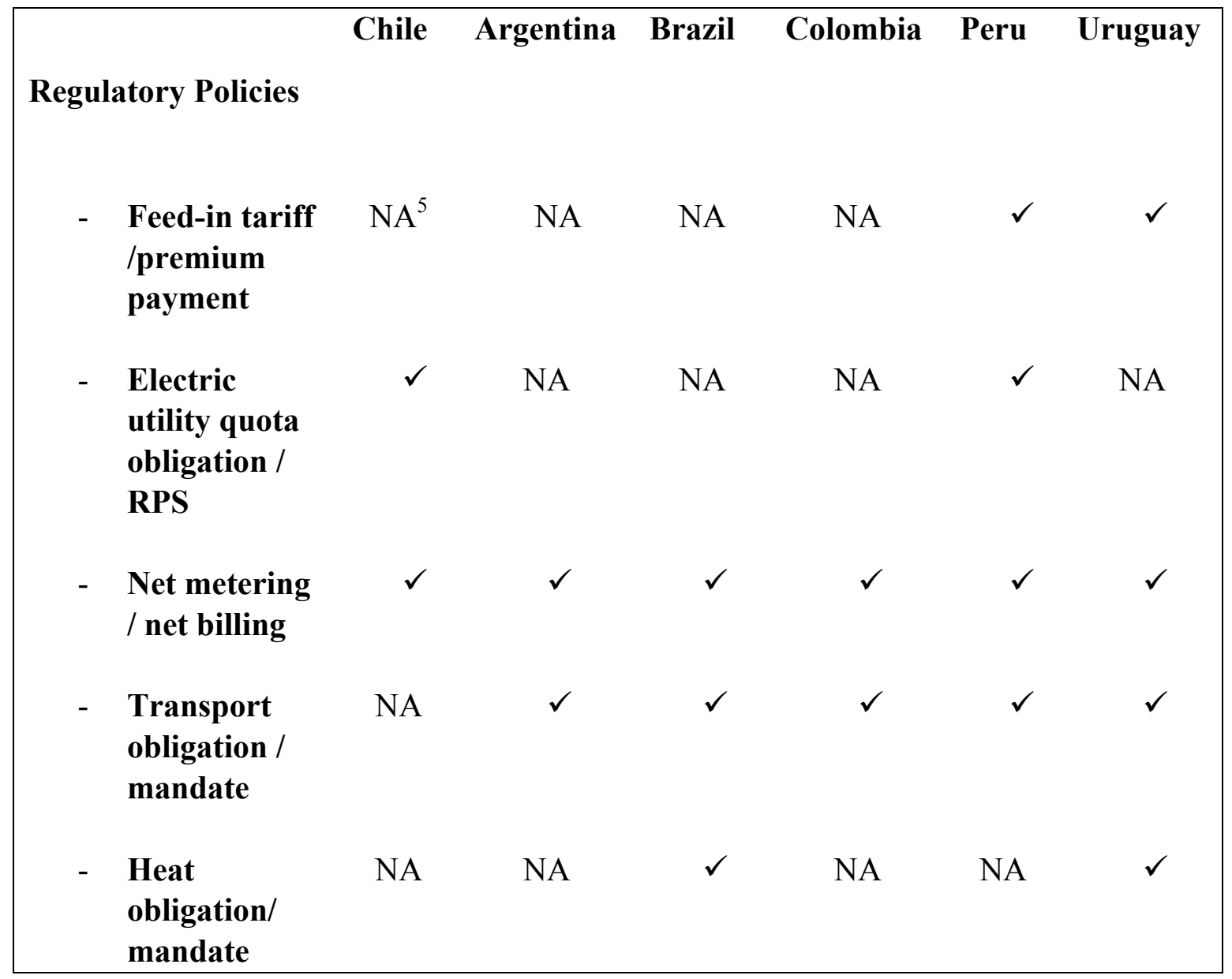

\footnotetext{
${ }^{5}$ Not Applied ( National or sub-national level)
} 


\begin{tabular}{|c|c|c|c|c|c|c|c|}
\hline- & $\begin{array}{l}\text { Tradable } \\
\text { REC }\end{array}$ & NA & NA & NA & NA & NA & NA \\
\hline- & Tendering & $\checkmark$ & $\checkmark$ & $\checkmark$ & NA & $\checkmark$ & $\checkmark$ \\
\hline \multicolumn{8}{|c|}{$\begin{array}{l}\text { Fiscal Incentives and } \\
\text { Public Financing }\end{array}$} \\
\hline - & $\begin{array}{l}\text { Capital } \\
\text { subsidy, } \\
\text { grant, or } \\
\text { rebate }\end{array}$ & $\checkmark$ & $\checkmark$ & NA & NA & NA & $\checkmark$ \\
\hline - & $\begin{array}{l}\text { Investment } \\
\text { or production } \\
\text { tax credits }\end{array}$ & $\checkmark$ & $\checkmark$ & $\checkmark$ & $\checkmark$ & NA & NA \\
\hline - & $\begin{array}{l}\text { Reductions in } \\
\text { sales, energy, } \\
\text { VAT or other } \\
\text { taxes }\end{array}$ & $\checkmark$ & $\checkmark$ & $\checkmark$ & $\checkmark$ & $\checkmark$ & $\checkmark$ \\
\hline - & $\begin{array}{l}\text { Energy } \\
\text { production } \\
\text { payment }\end{array}$ & NA & $\checkmark$ & NA & NA & NA & $\checkmark$ \\
\hline - & $\begin{array}{l}\text { Public } \\
\text { investment, } \\
\text { loans or } \\
\text { grants }\end{array}$ & $\checkmark$ & $\checkmark$ & $\checkmark$ & $\checkmark$ & $\checkmark$ & $\checkmark$ \\
\hline
\end{tabular}

\subsection{Restructuring of Power Auction System Design}

Another important reform in Chile was to improve renewable energy generators' ability to compete in energy auctions. Due to the high levels of initial investment required by renewable technologies, access to financing is crucial to the development of projects. 
However, many renewable energy projects without a power purchase agreement ("PPAs") used to face significant obstacles to obtain funding from commercial banks. In Chile, PPAs can be achieved by bilateral negotiations or through participation in " power auctions" carried by the National Energy Commission (CNE) - for regulated consumers served by the distribution companies. A "power auction" is a mechanism widely used in Latin American countries to grant energy projects based on competitive bids. Since 2005, Law 20,018, also known as "Short Law II" requires electricity distribution companies to contract their energy requirements by means of competitive nondiscriminatory auctions (thus including renewables). A submitted bid with the lowest price is awarded a long-term contract (typically, a power purchase agreement (PPA)) for the project. In 2014, important changes were introduced in the distribution tender process, where the government, for the first time, established time blocks in which renewable energy generators could bid their energy. Previous bidding processes had standards blocks of time that favored conventional generators, but today these processes are open to any source of power, increasing renewable generators' prevalence in the energy market. This modification favors renewable generators, as they can now contract during more times and are no longer only obligated to bid energy in 24-hour blocks. The contracts to be tendered, since then contain three blocks according to the time of day, with one block covering from $11 \mathrm{pm}$ to $8 \mathrm{am}$, a second from $8 \mathrm{am}$ to $6 \mathrm{pm}$, and a third at the time of peak demand between $6 \mathrm{pm}$ and $11 \mathrm{pm}$. This modification in the structure of the auction scheme has greatly favored renewable generators, since they could now offer during the times of day when they are producing energy. In the latest and also largest energy auction ever, the Chile National Energy Commission (CNE) targeted to add a total generation of $12,430 \mathrm{GWh} /$ year, consisting of five time blocks for 20 years from 2021, covering 30\% Chile's energy demand. Wind and solar photovoltaic (PV) projects were awarded around 
$40 \%$ of the energy of the auctions. The efficient and competitive nature of auctions have resulted in decreased energy costs, encouraging further investment in the sector. For the first time in the history of tendering, the average price reached the level of USD 47.6 /MWh which is $40 \%$ below the average price of USD 79.3 reached in the 2015 auction and $66 \%$ below the average price of USD 130/MWh reached in the 2013 auction. Moreover, this reform improved renewables' commercialization, facilitating renewable energy projects to obtain the needed commercial bank funding for their construction.

\subsection{Approval of a Transmission Law}

Another serious problem face by renewables energy projects is the access to the transmission system. The current transmission system presents significant limitations to renewable energy projects resulting in long delays in upgrading and expanding processes, mainly backed by lengthy tendering, permitting and construction processes. In addition, some difficulties in the interconnection procedures, deficiencies in the regulation of open access to transmission networks, and absence of standard pricing schemes for transmission, are the most urgent barriers to overcome. More recently, the Chilean parliament has also passed a law (Law 20936) on electricity transmission, which is expected to improve the electricity transmission system by addressing key constraints, which will benefit the development of the renewable energy industry. The new Law aims to create a robust interconnected transmission system allowing the unification of Chile's power grid to connect the Northern Interconnected System (SING) with the Central Interconnected System (SIC). The interconnection of the north and central grid systems will allow to merge two medium sized markets, not only forming a more competitive marketplace and including various player promoting renewable energy, but also 
addressing the growing energy needs in the center and north of the country. It will enable mining industries in the north of the country to access the existing surplus power from hydroelectric in the SIC and it will also allow the energy generated from large solar potentials in the north to be distributed to the central and southern part of the country. Alongside a new national interconnected power system, an independent transmission operator will be established to replace the current operators of the SIC and SING. In addition, the new law considers the charge of $100 \%$ of the transmission costs to consumers, instead of the current arrangement where generators bear these costs. This will grant greater competitiveness to renewable energy projects, since there will be no location signal that tend to benefit projects that are located near large demand centers, such as large thermoelectric plants.

\section{Policy recommendations}

The large increase in renewable energy investments over the last five years in Chile has been a remarkable shift to the decarbonization of its energy matrix. However, there are still significant concerns that need to be addressed in order to sustain this energy transition over the long run. For this purpose, in this section we discuss and propose several recommendations in the following areas:

\subsection{Consistent and right government support}

The experiences of various successful countries -like Denmark and Sweden- in renewable energy development, shows that an effective transition requires a combination of clear decision-making and consistency in government policy. Greater policy severity and consistency over time indicates a strong political will that minimize uncertainty and drive firms to invest in the future development of the renewable industry. The consistency of 
policies is also particularly relevant for achievement of long-term targets, ultimately allowing the energy transition to be accomplished. Thus, potentially impacting the rate of technological innovation deliverance and the development of strong domestic industries. Onand-off policies can create market boom-and-bust cycles, negatively impacting investment decisions. Yet, consistent support is never easy: for example, newer governments in Italy, Spain, and some U.S. states have challenged renewable energy policies passed by previous governments. Besides working toward energy policy consistency, Chile must also develop a policy portfolio to facilitate the renewable energy transition and achieve the multiple energy objectives rather than rely on a single solution for the country's power sector. Renewable energy support must be part of a broader policy package that can be integrated throughout the economy, including also the transportation and building sectors.

\subsection{Effective auction designs to encourage efficiency}

The restructuring reform on the power auction system was a good step forward to improve the commercialization of renewables in the market and to enhance competition. However, in recent auction some renewable companies offered energy well below generation costs in order to capture future market shares. From policymaker's perspective, promising very cheap electricity is a positive outcome, but it may overreached companies as banks and investors balk at the risks. The fulfillment of investment pledges by some companies that have won contracts to supply electricity remains a serious challenge for the sector. Lower prices are not enough. New projects must be commercially viable for companies to keep momentum and be sustainable in the long run. Therefore, the implementation of auction mechanisms must be closely controlled for predatory bidding or, worse still, market rigging. Chile must further bolster this policy. 


\subsection{A modern and flexible transmission network infrastructure}

In addition, a successful transition to a larger share of renewable energy sources requires a modern and flexible transmission network infrastructure. The recently enacted transmission law is a significant step forward. However, greater emphasis on ensuring consistency and transparency in long-term transmission planning, as well as creating a strategic vision for the development of market-driven transmission investment will benefit renewable energy development. The transmission planning has been historically just reactive to new projects and the incorporation of renewable projects requires a proactive planning.

\section{- Improvement of grid interconnection at national and international level:}

Successful transition to a larger share of renewable energy sources, including technologies such as wind and solar power, in the energy matrix of Chile is being slowed down by the need of a modern, robust and flexible transmission network infrastructure. The new regulations under the recently enacted transmission law are a key step forward to enabling the expansion and development of non-conventional renewable energy projects. Most importantly, the unification of the two grids -the Central (SIC) and North Interconnected grids (SING)- together with the creation of an Independent System Operator, replacing the Economic Load Dispatch Centers (CDEC), are expected to drive renewable generation. The interconnection of the two existing systems would enable more flexibility in power transmission from the northern region, making available an ample availability of solar energy

to the central region, where there is a high electricity demand. Another important benefit of a robust interconnection system is that it will help variable renewable energies to complement each other at different times (e.g. solar power during the day, wind power overnight) and/or in different regions (wind energy in the central-south region, solar energy in the north). 
Besides, higher interconnection and transmission capacity could help to provide the optimal use of surplus generation, to reduce the requirements for regulation reserves, to improve congestion management, and to decrease the need for back-up generation capacity.

Historically, commercial exchange of electricity has been quite limited among South American countries by both regulatory differences and different functioning of each market. In the case of Chile, interconnection with neighboring countries is only with Argentina and is currently not functioning. Building modern, high-voltage, direct-current (HVDC) transmission lines for long distances and establishing the mechanism of importing and exporting power among neighboring countries can play a relevant role in balancing renewable energy. Furthermore, this could allow to exploit the high potential for solar energy in the desert in northern Chile, as the energy could be exported to Bolivia and Argentina.

\section{- Improvements in local-level distribution systems}

In order to accommodate a large share of renewables, some technical improvements should be implemented in the local-level distribution systems. The experiences to date in large-scale integration of variable renewables in European countries with high wind and solar PV penetration, shows that two-way ("reverse") flows of power are the main challenge at the distribution level. Therefore, in order to cope with similar issues, distribution utilities in Chile will need to invest in grid upgrades, including substations, special tap-changing transformers, and power lines. Several additional measures, such as the implementation of smart grid technologies can play a crucial role in enabling the smooth integration of high shares of solar and wind technologies and supporting distributed generation. For example, some distribution utilities in Germany are testing smart inverters as a new approach to regulate voltage and reactive power in the distribution system. 


\subsection{Flexible electricity generation options}

The large increase in renewable energy projects over the last five years has been associated mostly to solar PV and wind energy. High penetration rates of these energy sources in the electricity generation matrix presents a great challenge for the design and operation of the power system. In particular, the intermittency of solar and wind energy raises challenges in terms of power network stability and reliability and grid integration between different regions. As a consequence, demand side management -likedemand response, intelligent energy systems, and smart loads- and more flexible electricity generation options should be implemented.

In this context, the already operating hydro dams could have a key role working as virtual batteries for solar and wind balancing and also reducing interregional electricity trade and electricity transmission costs (Reference). Among other possible solutions, the development of energy storage batteries has been recognized as one of the most promising approaches. Today, storage technologies are becoming increasingly relevant as the technologies passed the demo and prototype phases to start now a wide market implementation phase. The only remaining barrier for its implementation is the price tag of the storage systems, but even this barrier is quickly disappearing.

\subsection{Local balancing and ancillary services}

Historically, the energy has been regulated considering a two-product market that need to be financed in equilibrium, energy and capacity. The regulation has worked quite well with conventional power plants in terms of providing energy at marginal costs and generating the necessary incentives to invest in capacity. However, the fast and massive irruption of zero- 
operating-cost technologies might challenge the regulatory system to the point if making it obsolete. Large penetration of variable renewable energy generation and, in particular, wind generation, introduces increasing pressure for ancillary services in the power system. Variable generations have a restricted predictability and in order to cope with the forecast error, larger amounts of an appropriate capacity in reserve power plants and their flexible dispatch becomes increasingly important. Chile has recently implemented a limited fixedcompensation mechanism for primary and secondary frequency regulation, voltage regulation, and a cost-based compensation for black-start capability. This is an important first step in the right direction, but it is not enough. Since the penetration of intermitent renewable energies in the power system is increasing, it is necessary to develop market-based mechanisms for pricing these important servicest.

\subsection{Better system control software and weather forecasting tools}

A higher penetration of renewable energy in the electricity grids, increases the need for the development and implementation of an adequate software with analytical tools and forecasting mechanisms to accommodate the injection of electricity generated by solar and wind power plants. One of the impacts of high shares of renewables is that, for example, the power system in Germany experienced much higher system ramp up rates than in the past, up to $1800 \mathrm{MW}$ per hour, due to swings in renewable power output. In order to guarantee a stable operation of the electricity system and keeping costs resulting from generation reserves to a minimum, the Chilean System Operators should successfully implement new forecasting analyses and improve its software tools.

\section{Conclusions}


The increasing risk of stable hydropower generation due to droughts caused by climate change, the heavy dependence on fossil energy imports with volatile prices, and the increasing environmental and social opposition to mega energy projects have put significant pressure on the Chilean government to start considering alternative sources of energy.

As a result, the introduction of incentives to foster renewable energy supplies ( e.g. approval of RPS law, the redesign of power auctions, and the approval of a new transmission law, have transformed the country into a hotbed of renewable energy investment in the region. Although Chile currently leads the market-driven transition to renewables, still needs to appropriately address a multitude of cross-cutting barriers to complete its shift toa completely sustainable energy matrix. An effective transition requires a good combination of clear decision-making, consistency in government policies, greater emphasis on solving the implementation challenges of energy auctions, long-term planning, and a commitment to tackling transmission challenges to accommodate large amounts of renewable energies in the power system.

\section{Funding}

The authors acknowledge receipt of the following financial support for the research, authorship, and/or publication of this article: This work was funded by the Research Grant CONICYT/FONDAP/15110019. 


\section{References}

Barbosa LdSNS, Bogdanov D, Vainikka P, Breyer C. 2017. Hydro, wind and solar power as a base for a 100\% renewable energy supply for South and Central America. PLoS ONE 12(3): e0173820. https://doi.org/10.1371/journal.pone.0173820

Frankfurt School-UNEP Centre/BNEF, 2016. Global Trends in Renewable Energy Investment 2016

REN21 Secretariat, 2016. Renewables 2016 Global Status Report. Paris, France

National Energy Comission of Chile (CNE), 2016. Statistics/ Electricity

The National Centre for Innovation and Promotion of Sustainable Energy (CIFES in Spanish), 2016. CIFES reports 2013-2016. Santiago Chile

Organisation for Economic Co-operation and Development (OECDa). 2016. Environmental Performance Reviews: Chile 2016. Paris, France

World Bank Group. World Development Indicators, Chile; World Bank Group: Washington, DC, USA, 2013.

Raineri, R, 2007 (4th quarter). Chronicle of a Crisis Foretold: Energy Sources in Chile. IAEE Forum pp 27-30 
Nasirov, S., and Silva, C. (2014, 4th quarter). Diversification of Chilean energy matrix: Recent developments and challenges. IAEE Forum, pp. 27-31.

Load Economic Dispatch Center (CDEC): CDEC-SING http://www.cdec-sic.cl/ and CDEC -SIC http://www.cdec-sing.cl/

Villarino, J., 2012. Energy and Mining in Chile. ENERMIN 2012 - 2nd International Seminar on Energy Management in the Mining Industry.

OECD Environmental Performance Reviews: Chile 2016, Paris, France.

Lostarnau, C., J Oyarzún, H. Maturana, G. Soto, M. Señoret, M. Soto, T.S. Rotting, J.M. Amezaga, and R. Oyarzín, 2011. "Stakeholder Participation within the Public Environmental System in Chile: Major Gaps between Theory and Practice", Journal of Environmental Management 92.

Nelson, M. (2013), "Fifty Years of Hydroelectric Development in Chile: A History of Unlearned Lessons", Water Alternatives 6(2)

Orellana, M. (2005), “Indigenous Peoples, Energy, and Environmental Justice: The Pangue/Ralco Hydroelectric Project in Chile's Alto BioBio”, Journal of Energy and Natural resources Law 23(4) 